\title{
Late-onset retinal degeneration
}

INSERM

\section{Source}

INSERM. (1999). Orphanet: an online rare disease and orphan drug data base. Late-onset retinal degeneration. ORPHA:67042

Late-onset retinal degeneration is an inherited retinal dystrophy characterized by delayed dark adaptation and nyctalopia and drusen deposits presenting in adulthood, followed by cone and rod degeneration that presents in the sixth decade of life, which leads to central vision loss. Anterior segment features such as peripupillary iris transillumination defects and abnormally long anterior zonular insertions are also observed. Choroidal neovascularization and glaucoma may occur in the late stages of the disease. 